\title{
DIREITOS HUMANOS E EDUCAÇÃO: \\ A POLÊMICA EM TORNO DA PROVA DE REDAÇÃO \\ DO ENEM 2015 E 2017
}

\author{
HUMAN RIGHTS AND EDUCATION: \\ THE CONTROVERSY AROUND ENEM'S THE WRITING TEST \\ IN 2015 AND 2017
}

\section{Cynthia Agra de Brito Neves*}

\section{RESUMO}

Este artigo visa realocar na agenda contemporânea a urgência de se priorizar uma Educação em Direitos Humanos (EDH), tal como prevê a nossa Constituição Federal e a Lei de Diretrizes e Bases da Educação (LDB nº 9.394/1996) vigentes, sobretudo na conjuntura atual, em que a democracia brasileira encontra-se ameaçada. Exemplos de cunho fascista não faltam no setor educacional, haja vista o sucesso de programas como Escola Sem Partido ou Escola Livre, que têm angariado adeptos tanto na sociedade civil quanto na política, fazendo emplacar projetos de leis em todas as esferas do legislativo. O Exame Nacional do Ensino Médio (ENEM) foi vítima da falsa "neutralidade ideológica" pregada por esses movimentos em 2015 e em 2017. Em 2017, por exemplo, o Escola Sem Partido conseguiu proibir a atribuição de nota zero aos alunos que desrespeitassem os Direitos Humanos na prova de redação do ENEM, conforme previsto no edital do exame, o que foi legitimado, às vésperas da avaliação nacional, pela atual presidente do Supremo Tribunal Federal (STF). Este trabalho se coloca, por um lado, no dever de contextualizar os avanços conquistados na direção de uma Educação em Direitos Humanos (EDH), por meio da implementação de três documentos-chave, como: o Programa Nacional de Direitos Humanos (PNDH, 1996, 2002 e 2009), o Plano Nacional de Educação em Direitos Humanos (PNEDH, 2003 e 2006) e as Diretrizes Nacionais para a Educação em Direitos Humanos (DNEDH, 2012); por outro, coloca-se no dever de alertar para os retrocessos que a educação nacional tem sofrido recentemente, quando estratégias de censura e controle têm funcionado para silenciar e perseguir professores ou para manipular alunos em nome de uma suposta liberdade de expressão. Defendo, portanto, que a Linguística Aplicada deva encorajar não apenas um "letramento em direitos humanos" (ABREU, 2015), mas um "letramento ideológico" (STREET, 2014) em direitos humanos.

Palavras-chave: Direitos Humanos, Educação, ENEM.

\section{ABSTRACT}

This article aims to reallocate into the contemporary agenda the urgency of prioritizing Human Rights Education (EDH), as foreseen in our Federal Constitution and the Law on

\footnotetext{
* Universidade Estadual de Campinas, Campinas (SP), Brasil. cynthiaagrabneves $@$ gmail.com.
} 
Guidelines and Bases of Education (LDB n ${ }^{\circ}$ 9.394/1996), in the current situation, in which Brazilian democracy is threatened. Fascist examples are abundant in the educational sector, given the success of programs such as School Without Party or Free School, which have garnered adherents in both civil society and politics, and have put forward draft laws in all spheres of the legislature. The National High School Examination (ENEM) fell victim to the false "ideological neutrality" preached by these movements in 2015 and 2017. In 2017, for example, the School Without Party was able to prohibit the assignment of zero marks to students who disrespected Human Rights in the writing test of the ENEM, as foreseen in the announcement of the examination, which was legitimized, on the eve of the national evaluation, by the current President of the Supreme Federal Court (STF). This work focuses, on one hand, on the duty to contextualize the advances achieved in the field of Human Rights Education (EDH), through the implementation of three key documents, such as the National Human Rights Program (PNDH, 1996, 2002 and 2009), the National Plan for Human Rights Education (PNEDH, 2003 and 2006) and the National Guidelines for Human Rights Education (DNEDH, 2012); on the other hand, has a duty to warn of the setbacks that national education has recently undergone, when strategies of censorship and control have worked to silence and persecute teachers or to manipulate students in the name of supposed freedom of expression. I therefore advocate that Applied Linguistics should encourage not only a "human rights literacy" (ABREU, 2015), but a "ideological literacy" (STREET, 2014) in human rights.

Keywords: Human Rights, Education, ENEM.

\section{INTRODUÇÃO}

O senhor entende, o que conto assim é resumo; pois, no estado de viver, as coisas vão enqueridas com muita astúcia: um dia é todo para a esperança, o seguinte para a desconsolação. (ROSA, 1967, p. 310)

Em 1995, Antonio Candido publicava o seu célebre artigo intitulado "O direito à literatura", no qual o crítico relacionava "Direitos Humanos e literatura" no sentido de defender o direito à literatura como um Direito Humano. Apesar de reconhecer que, naquela época, se vivia, paradoxalmente, uma barbárie em meio a um mundo civilizado, o autor demonstra um certo otimismo ao afirmar, por exemplo, que "os tribunais de Nuremberg foram um sinal dos tempos novos", pois o homem já não acha mais tão natural fazer afirmações do tipo "haver pobres é vontade de Deus" nem que "empregados domésticos não precisam descansar, por isso não têm necessidade de folga aos domingos, pois se não estão acostumados, não sentem falta", ou ainda, "só morre de fome quem for vadio".

Ainda em tom de esperança, Candido diz acreditar haver até mesmo uma nova atitude diante do pobre, do esfarrapado e do negro, que não têm ocupado mais as 
caricaturas de jornais e revistas nem têm sido alvo predileto de piadas. E nessa toada utópica, o ensaísta explica que políticos e empresários têm mudado de postura com relação à desigualdade e à injustiça sociais, uma vez que a "insensibilidade em face da miséria deve ser pelo menos disfarçada" para que não comprometa a imagem deles. Na lógica do autor, é aí que entra o problema dos direitos humanos:

\begin{abstract}
Por quê? Porque pensar em direitos humanos tem um pressuposto: reconhecer que aquilo que consideramos indispensável para nós é também indispensável para o próximo. Esta me parece a essência do problema, inclusive no plano estritamente individual, pois é necessário um grande esforço de educação e auto-educação a fim de reconhecermos sinceramente este postulado. Na verdade, a tendência mais funda é achar que os nossos direitos são mais urgentes que os do próximo. (CANDIDO, 1995, p. 174)
\end{abstract}

Candido (1995) finalmente desmascara o egoísmo humano: de modo geral, as pessoas concordam que todos têm direito a bens fundamentais, que asseguram a sobrevivência física dignamente, os chamados "bens incompressíveis", como casa, comida, roupa, saúde; porém, não consideram igualmente relevante aos seus semelhantes o direito aos "bens compressíveis", isto é, o direito aos cosméticos, aos enfeites, às roupas extras, a ler Dostoievski ou a ouvir Beethoven, exemplifica o autor. Isso porque quando pensam em seus direitos não suportam a ideia de incluir seus semelhantes - daí a importância da reflexão sobre os direitos humanos.

Contrariando o senso comum e a expectativa das classes dominantes, o crítico alarga o sentido de "bens compressíveis". Para ele, não se trata apenas daqueles direitos que asseguram a sobrevivência física decentemente, mas também os que garantem a integridade espiritual. "São incompressíveis certamente a alimentação, a moradia, o vestuário, a instrução, a saúde, a liberdade individual, o amparo da justiça pública, a resistência à opressão etc.; e também o Direito à crença, à opinião, ao lazer e, por que não, à arte e à literatura". (CANDIDO, 1995, p. 176)

E cada época, cada cultura, continua o autor, determinam critérios de incompressibilidade, que estão ligados à divisão da sociedade em classes. Desse modo, até "a educação pode ser instrumento para convencer as pessoas de que o que é indispensável para uma camada social não o é para outra" (p. 175). Do ponto de vista individual, adverte-nos, é importante ter consciência de que os pobres e desvalidos têm direito aos bens materiais e à igualdade de tratamento; do ponto de vista social, é preciso haver leis específicas que garantam isso, reivindica. "A luta pelos direitos humanos pressupõe a consideração de tais problemas" (CANDIDO, 1995, p. 176).

Em seguida, o autor discorre sobre o propósito nuclear de seu texto: defender o "direito à literatura" como um "bem incompressível", isto é, como um "direito 
humano". Não se pretende, neste artigo, sustentar essa linha de argumentação, como já feito em outros trabalhos de pesquisa (cf. p.ex. NEVES, 2014). Retomo Antonio Candido aqui para constatar e lamentar que essa sociedade dos anos 1990 desenhada por ele inicialmente já não se reconhece mais. O Brasil vive hoje, aproximadamente duas décadas após a publicação do texto de Candido, tempos sombrios de extremo conservadorismo e retrocesso, em que o desrespeito aos direitos humanos impera em diversos setores da sociedade: da política à educação. Este artigo pretende tratar justamente dessa relação.

\section{DIREITOS HUMANOS E ESCOLA SEM PARTIDO: RETROCESSOS À VISTA}

A nossa Constituição Federal ${ }^{1}$ e a Lei de Diretrizes e Bases da Educação $\left(\mathrm{LDB} \mathrm{n}^{\circ}\right.$ 9.394/1996)² deixam evidentes a preocupação em educar para a cidadania, comumente entendida como um conjunto de direitos e deveres que implica participação na vida pública e política. O termo, reconhecem Ana Rita S. Prata e Paula S. M. de Souza (2018), cada vez mais se entrelaça à ideia de Direitos Humanos, ou seja, a um conjunto de direitos consolidados pelo Estado Democrático de Direito, que visam à garantia de uma vida digna a todas as pessoas. As autoras, que são Defensoras Públicas do Estado de São Pauloº, explicam que educar para a cidadania não se restringe a educar para o trabalho, mas sim preparar os educandos para o respeito ao outro, às diferenças, prepará-los para refletir criticamente sobre o mundo, caso contrário, advertem-nos, ao futuro restará uma massa acrítica, mansa, incapaz de defender e reivindicar seus próprios direitos. Ao fim e ao cabo, o que as autoras estão defendendo é o que Brian Street (2014) chama de letramento crítico e ideológico, e que nada tem a ver com "doutrinação político-partidária", tal como acusa os educadores o programa Escola Sem Partido (ESP), um movimento fundado em 2014 por Miguel Nagib, que tem ganhado vez e voz na atualidade.

1. Art. 205: "A educação, direito de todos e dever do Estado e da família, será promovida e incentivada com colaboração da sociedade, visando ao pleno desenvolvimento da pessoa, seu preparo para o exercício da cidadania e sua qualificação para o trabalho". Disponível em: https:/www2.senado.leg. br/bdsf/bitstream/handle/id/518231/CF88_Livro_EC91_2016.pdf. Acesso fev. 2018.

2. Art. $2^{\circ}$ : "A educação, dever da família e do Estado, inspirada nos princípios de liberdade e nos ideais de solidariedade humana, tem por finalidade o pleno desenvolvimento do educando, seu preparo para o exercício da cidadania e sua qualificação para o trabalho". Disponível em: http://portal.mec. gov.br/seesp/arquivos/pdf/lei9394 ldbn1.pdf. Acesso fev. 2018.

3. Agradeço à colega Roberta Gregoli, Doutora pela Universidade de Oxford (2014), atualmente Professora Colaboradora da UnB, pela generosidade em compartilhar o documento recém-publicado sobre o Direito das mulheres: igualdade de gênero na educação e liberdade de expressão, nos Cadernos da Defensoria Pública do Estado de São Paulo, v. 3, n. 8, 2018. Disponível em: https://www.defensoria.sp.def.br/cadernos_defensoria/volume8. aspx. Acesso em fev. 2018. 
O escolasempartido.org se auto-define como uma associação informal, independente, sem fins lucrativos e sem qualquer vinculação política, ideológica ou partidária. Miguel Nagib, fundador e atual presidente, explica se tratar de uma reação à contaminação político-ideológica nas escolas brasileiras, do ensino básico ao superior. Programas desse tipo (Escola Sem Partido, Escola Livre, De Olho no Livro Didático, dentre outros de cunho religioso como a Igreja Videira e o Instituto Plínio Correia de Oliveira) se espalham pelo Brasil afora pregando discursos em prol de uma educação que deva seguir uma "neutralidade ideológica" - como se isso fosse possível - e respeitar as convicções morais e religiosas dos pais de cada aluno. Infelizmente, essa bandeira fascista levantada pela neutralidade no ensino tem seduzido muitos pais de alunos, coordenadores, diretores e gestores de escolas públicas e particulares, e consequentemente, tem colocado professores em situações constrangedoras de censura e controle: "se correm", são perseguidos, "se ficam", são silenciados. A ameaça não está apenas na educação básica, as universidades também sentem a sua liberdade de cátedra intimidada ${ }^{4}$.

Sem dúvidas, tal proposta de uma educação neutra fere o ideal democrático constitucional. Entretanto, diversos projetos de leis estaduais e municipais ${ }^{5}$ tramitam em Assembleias Legislativas de todo país, visando cercear políticas públicas e programas educacionais voltados à promoção da igualdade e dos direitos sexuais e reprodutivos de jovens estudantes. São leis encabeçadas por políticos religiosos - muitas vezes, associados a programas como o próprio Escola Sem Partido ou a

4. Refiro-me aqui a um caso pessoal de que fui vítima na Unicamp em 2017, quando um pai de uma aluna do ProFIS (Programa de Formação Interdisciplinar Superior) ligou para a Secretaria do curso e fez uma ameaça anônima a minha pessoa dizendo em tom de voz alterado ao telefone que "acabaria com minha vida" caso eu continuasse a propor assuntos em sala de aula que remetessem à homossexualidade. Provavelmente, a intolerância desse pai se deveu aos textos trabalhados no curso, a saber: o artigo científico "Museus e diversidades sexual: reflexões sobre mostra LGBT e queer" (cf. PINTO, R. (2012) Revista de Arqueologia Pública, v. 5, n. 1, pp. 44-55) e o curta-metragem "Eu não quero voltar sozinho" (roteiro e direção de Daniel Ribeiro). O caso foi levado à polícia e um Boletim de Ocorrência foi registrado. O episódio teve ampla repercussão não apenas no ambiente acadêmico - o Instituto de Estudos da Linguagem (IEL) escreveu uma moção de repúdio ao ocorrido - como também nas mídias: saiu a notícia em jornais nacional e internacional. Registro aqui também, neste artigo, minha indignação com o ocorrido e temo pelo futuro da democracia no Brasil atualmente.

5. Desde 2014, há 62 projetos de lei (PLs) relacionados ao movimento Escola Sem Partido tramitando no Congresso Nacional e nas casas legislativas de pelo menos 12 estados e 23 cidades do país. São Paulo é o estado que mais tem PLs desse tipo (total 3); Ceará, Espírito Santo, Pernambuco, Rio de Janeiro e Distrito Federal têm 2 PLs cada. Em Campo Grande e Belo Horizonte, tramitam 3 PLs. Em Alagoas, a lei "Escola Livre" chegou a ser aprovada em Assembleia Estadual, mas depois recebeu o parecer de inconstitucionalidade pelo Supremo Tribunal Federal (STF). Os municípios de Santa Cruz do Monte Castelo (PR) e Picuí (PB) tiveram seus PLs aprovados em 2016. (Disponível em: http://www.deolhonosplanos.org.br/projetos-lei-escola-sem-partido/. Acesso em fev. 2018). 
organizações como o Movimento Brasil Livre (MBL) - contrários ao ensino, em ambiente escolar, de conteúdos relacionados à sexualidade humana, à identidade de gênero e ao pluralismo de ideias e concepções pedagógicas" ${ }^{\prime \prime}$.

Eles criminalizam os professores acusando-os de fomentar a "ideologia de gênero" - expressão que utilizam para se referirem a temas como "identidade de gênero" e "diversidade sexual" - e sugerem "armas" para flagrar os "doutrinadores" e instruções para "coletar provas" e "planejar a denúncia", além de um modelo de "notificação extrajudicial" anônima para os pais que desejem denunciar professores que estão descumprindo os "Deveres do Professor" ${ }^{\text {"10, }}$, segundo o manual do Escola Sem Partido. A tática do silenciamento é bastante inteligente, uma vez que incita o medo - a mesma utilizada pelos militares na ditadura de 1964, relembram-nos Prata e Souza (2018). Desse modo, muitos educadores, constrangidos, acabam cedendo à censura e ao controle, já que nem sempre recebem o devido apoio das escolas: na rede pública de ensino, são submetidos a procedimentos administrativos; na rede privada, são demitidos - eis a fraqueza da nossa instituição escolar.

O acinte maior se deu antes e após a aprovação do Plano Nacional de Educação (PNE) em 2014 ${ }^{11}$. Desde 2013, quando foi apresentado ao Congresso, o PNE recebeu críticas e alimentou discussões entre os parlamentares, o que se estendeu até 2015. Uma vez publicado, sofreu pressão dos afiliados a esses movimentos que, por meio da proposta do PL 2731/2015, exigiam a retirada, no texto do PNE, de quaisquer expressões que remetessem à "ideologia de gênero". A tensão continuou até que houve mudanças no texto: o PNE ao invés de afirmar "a promoção da igualdade racial, regional, de gênero e de orientação sexual", optou por um termo mais genérico, como coibir "todas as formas de discriminação" deve ser um dos objetivos das políticas de educação para os próximos dez anos. Não é que o PNE proibiu o gênero no currículo, mas modalizou o seu texto, o que soou como um recuo às lutas por políticas públicas não sexistas, antirraciais e antidiscriminatórias na educação, e quem perde com isso são os direitos humanos. Como explicam as advogadas Ingrid V. Leão e Sandra Lia L. B. Barwinski:

6. Cf. Procuradoria Federal dos Direitos do Cidadão (PFDC/MPF), em Cadernos da Defensoria Públicado Estado de São Paulo, v. 3, n. 8, p. 33-55, fev. 2018.

7. Cf. em http://escolasempartido.org/flagrando-o-doutrinador. Acesso em fev. 2018.

8. Cf. em http://escolasempartido.org/planeje-sua-denuncia. Acesso em fev. 2018.

9. Cf. em http://www.escolasempartido.org/artigos-top/552-modelo-de-notificacao-extrajudicialarma-das-familias-contra-a-doutrinacao-nas-escolas. Acesso em fev. 2018.

10. Cf. em http://escolasempartido.org/deveres-do-professor. Acesso em fev. 2018.

11.Disponível em: http://pne.mec.gov.br/images/pdf/pne_conhecendo_20_metas.pdf. Acesso em fev. 2018. 
Gênero é uma categoria de análise das relações sociais. Esses estudos embora se localizem nas ciências sociais não se restringem a uma única área do conhecimento, são interdisciplinares; por isso, falar de gênero também se relaciona com pensar os direitos humanos ou defendêlos e torna-se difícil o seu isolamento ou proibição. (...) Em resumo, a palavra gênero começou a circular porque as análises sobre as relações de gênero na sociedade são úteis conhecimentos para entender a exclusão de pessoas, a experiência da violência e a comunicar sobre as desigualdades na sociedade. Por conta disso, chegou às políticas educacionais o reconhecimento de que existem discriminações e desigualdades de gênero. (LEÃO e BARWINSKI, 2018, p. 59-60)

Daí a importância de se construir uma escola livre, plural e democrática, que respeite todas as diferenças, que seja comprometida com o fim da violência contra a mulher, com fim da violência racista, com o fim da violência aos $\mathrm{LGBTI}_{\text {; }}$ uma escola que se posicione contra toda e qualquer forma de discriminação a grupos vulneráveis da sociedade brasileira, afinal, "todas essas relações sociais também estão no cotidiano escolar", afirmam Leão e Barwinski (2018, p. 60). Ao retirar do texto a palavra "gênero" o PNE deu um passo para trás e foi mal interpretado. O Ministério da Educação (MEC) tentou remediar e contra-atacar divulgando um cartaz com o seguinte enunciado: "Professor@ ninguém pode lhe impedir de discutir gênero e sexualidade na escola. Se for intimidad@, denuncie: Central de Atendimento Ministério da Educação 0800-616161 / secadi@mec.gov.br ${ }^{\prime \prime 2}$. O efeito, contudo, não foi o mesmo.

Em julho de 2016, o Instituto de Desenvolvimento e Direitos Humanos $(\mathrm{IDDH})^{13}$ fez uma denúncia aos Relatores de Educação e Liberdade de Expressão para alertar sobre o perigo dos projetos de lei que estavam tramitando no Brasil embasados pelo programa Escola Sem Partido. Um documento foi elaborado, em parceria com outras organizações ${ }^{14}$, no qual se registrava a denúncia de que o Escola Sem Partido violava direitos humanos básicos, como a liberdade de expressão e o direito à educação, impedindo a escola de ser um espaço plural de conhecimento,

12.Cf. em entrevista a Fenando Penna, professor da Faculdade de Educação da Universidade Federal Fluminense (UFF). Disponível em: http://educacaointegral.org.br/reportagens/projeto-de-leipreve-prisao-de-docente-que-falar-sobre-ideologia-de-genero/. Acesso em maio 2016.

13. O IDDH é uma organização não-governamental, sem fins lucrativos, fundada em 2004, em Joinville-SC, que tem como propósito promover uma educação para a cidadania e direitos humanos no Brasil. Sua missão é desenvolver materiais e metodologias para compartilhar conhecimento, bem como articular e acompanhar políticas públicas que garantam uma educação para a cidadania, visando uma sociedade igualitária, pacífica, justa e sustentável para todas as pessoas no Brasil. O IDDH tem assento no Comitê Nacional de Educação em Direitos Humanos (CNEDH), é membro do NGO Working Group on Human Rights Education and Learning (Genebra/Suíça) e possui status consultivo na Organização das Nações Unidas (ONU). Informações disponíveis em https://iddh. org.br/instituto/. Acesso em fev. 2018.

14.A CLADEM Brasil, Clínica de Direitos Humanos da PUC/SP, NUDEM, ECOS, GELEDES, AÇÃO EDUCATIVA e deFEMde. 
que forma sujeitos críticos e conscientes, capazes de compreender e refletir o mundo diverso em que vivem.

Desde então, contextualiza-nos Fernanda Lapa (2018, p. 87), o IDDH tem feito incidência, tanto no âmbito nacional quanto no internacional, "para alertar sobre os riscos existentes na ideia de neutralidade na educação, o que viola, no mínimo, o pluralismo de ideias e a diversidade de pensamento". Em 7 de abril de 2017 ocorreu uma pré-sessão da Revisão Periódica Universal das Nações Unidas (RPU) em Genebra, na qual o IDDH foi selecionado para falar sobre a situação dos direitos humanos no nosso país. Em seu depoimento, o Instituto denunciou as violações ocorridas no Brasil em relação ao direito à Educação, à Educação em Direitos Humanos e à Educação de gênero. Ainda na mesma semana, nos informa Lapa (2018), o IDDH visitou o Alto Comissariado das Nações Unidas para os Direitos Humanos a fim de reforçar a denúncia de censura à educação de gênero e orientação sexual, acusando, mais uma vez, o projeto Escola Sem Partido pelo desrespeito à educação em direitos humanos.

Na semana seguinte, dia 13 de abril, os Relatores da Educação, Liberdade de Expressão e Liberdade Religiosa da ONU fizeram uma Carta ao Estado Brasileiro em que questionaram a censura ocorrida nas escolas e o programa Escola Sem Partido. Lapa (2018) afirma que houve uma reação bastante negativa dos órgãos internacionais sobre a retirada da terminologia de gênero e orientação sexual de muitos planos de educação (municipais, estaduais e federal) do Brasil, bem como da Base Nacional Comum Curricular (BNCC). Graças a essa pressão internacional iniciada nas Nações Unidas, a Comissão Interamericana de Direitos Humanos solicitou ex officio uma audiência com o Estado Brasileiro, em 25 de maio de 2017, para tratar do tema: "Direitos Humanos e Educação livre, plural e sem censura no Brasil: a proposta de exclusão da perspectiva de identidade de gênero e orientação sexual da Base Nacional Curricular Comum e o Projeto Escola Sem Partido". O IDDH foi, mais uma vez, a ONG selecionada para tratar do tema e destacar as violações aos direitos à educação e à educação em direitos humanos.

Lapa (2018), que é uma das fundadoras e atualmente coordenadora executiva do IDDH, confessa sua indignação ao constatar que mesmo com toda manifestação, nacional e internacional, contra esse movimento conservador chamado Escola Sem Partido, os documentos oficiais de educação continuam não reforçando os termos para defender uma educação de gênero. Compartilho com a autora essa indignação, o que me faz novamente refletir sobre a sociedade descrita por Antonio Candido na introdução deste artigo. De certo, havia ideologias dessa estirpe naquela sociedade. A diferença é que nos anos 1990 os fascistas eram silenciosos. Hoje eles se sentem à 
vontade para divulgar suas ideias em sites, blogs e redes sociais, com direito a páginas no facebook e instagram. E como se isso não bastasse, ainda se vestem de verde e amarelo e vão para as ruas a fim de golpear nossa democracia. Se no século passado Candido (1995) defendia a literatura como direito humano; no século atual, tornase urgente defender os direitos humanos.

\section{DIREITOS HUMANOS E EDUCAÇÃO: AVANÇOS NO MEIO DO CAMINHO}

Para se promover uma política pública de Educação em Direitos Humanos $(\mathrm{EDH})$, três documentos oficiais foram elaborados e se tornaram basilares para a educação no Brasil, quais sejam: o Programa Nacional de Direitos Humanos (PNDH, 1996, 2002 e 2009) ${ }^{15}$, o Plano Nacional de Educação em Direitos Humanos $\left(\mathrm{PNEDH}, 2003\right.$ e 2006) ${ }^{16}$ e as Diretrizes Nacionais para a Educação em Direitos Humanos (DNEDH, 2012) ${ }^{17}$. Todos representaram, nas suas devidas proporções, avanços no caminho para se fortalecer uma $\mathrm{EDH}$.

Primeiramente, tivemos três versões do $\mathrm{PNDH}$, sendo que cada uma significou um aperfeiçoamento: a primeira, de 1996, fundou a Secretaria de Direitos Humanos (SDH) no Ministério da Justiça, com o objetivo de gerenciar as ações do próprio PNDH. A segunda versão saiu em 2002 e a terceira em 2009, ambas incluíram temáticas diversas acerca dos direitos humanos, dentre elas, a necessidade de criação de um Plano Nacional de Educação em Direitos Humanos (PNEDH) e de elaboração das Diretrizes Nacionais para a Educação em Direitos Humanos (DNEDH). Em síntese:

O PNDH-1 de 1996 tinha o foco voltado para os direitos civis e políticos, a saber: 1) Políticas públicas para a proteção e promoção dos Direitos Humanos (incluindo a proteção do direito à vida, liberdade e igualdade perante a lei); 2) Educação e cidadania: bases para uma cultura dos Direitos Humanos; 3) Políticas internacionais para a promoção dos Direitos Humanos; e 4) Implementação e monitoramento do Programa Nacional de Direitos Humanos.

O PNDH-2, de 2002, incorporou alguns temas destinados à conscientização da sociedade brasileira com o fito de consolidar uma cultura de respeito aos direitos humanos, tais como cultura, lazer, saúde, educação, previdência social, trabalho, moradia, alimentação, um meio ambiente saudável.

15.Disponível em: http://www.sdh.gov.br/assuntos/direito-para-todos/programas/pdfs/programanacional-de-direitos-humanos-pndh-3. Acesso em fev. 2018.

16. Disponível em http://portal.mec.gov.br/index.php?option=com docman\&view $=$ download\&alias $=2191$ - plano-nacional-pdf\&category slug $=$ dezembro-2009pdf\&Itemid=30192. Acesso em fev. 2018.

17. Disponível em: http://www.sdh.gov.br/assuntos/conferenciasdh/12a-conferencia-nacional-dedireitos-humanos/educacao-em-direitos-humanos/caderno-de-educacao-em-direitos-humanosdiretrizes-nacionais. Acesso em fev. 2018. 
O PNDH-3 $3^{18}$ é lançado em 2009 e é importante ferramenta para consolidação dos direitos humanos como política pública. O Brasil avançou na materialização das orientações que possibilitaram a concretização e a promoção dos Direitos Humanos. Configura-se como avanço a interministerialidade de suas diretrizes, de seus objetivos estratégicos e de suas ações programáticas (BRASIL, 2013, p. 23).

Já o PNEDH, lançado primeiramente em 2003 e revisado em 2006, é resultado do trabalho do Comitê Nacional de Educação em Direitos Humanos (CNEDH), vinculado à Secretaria de Direitos Humanos (SDH), que reúne especialistas na área e tem como princípios "o combate à discriminação e a promoção da igualdade entre as pessoas e a afirmação de que os direitos humanos são universais, indivisíveis e interdependentes" (BRASIL, 2003, p. 6) A SDH desenvolve ações e projetos que visam proteger, garantir e promover os direitos humanos dos cidadãos, em especial, de grupos mais vulneráveis e em situação de risco: combate o trabalho escravo e protege os direitos de crianças, adolescentes, idosos, homossexuais, afrodescendentes, mulheres e pessoas com deficiência física. Os sete objetivos gerais propostos em 2003 foram ampliados para treze no PNEDH de 2006, conforme esquematizado no quadro abaixo:

Quadro 1. Objetivos gerais da PNEDH (BRASIL, 2006, p. 26-27)

PNEDH - OBJETIVOS GERAIS

1) destacar o papel estratégico da educação em direitos humanos para o fortalecimento do Estado Democrático de Direito;

2) enfatizar o papel dos direitos humanos na construção de uma sociedade justa, equitativa e democrática;

3) encorajar o desenvolvimento de ações de educação em direitos humanos pelo poder público e a sociedade civil por meio de ações conjuntas;

4) contribuir para a efetivação dos compromissos internacionais e nacionais com a educação em direitos humanos;

5) estimular a cooperação nacional e internacional na implementação de ações de educação em direitos humanos;

6) propor a transversalidade da educação em direitos humanos nas políticas públicas, estimulando o desenvolvimento institucional e interinstitucional das ações previstas no $\mathrm{PNEDH}$ nos mais diversos setores (educação, saúde, comunicação, cultura, segurança e justiça, esporte e lazer, dentre outros);

7) avançar nas ações e propostas do Programa Nacional de Direitos Humanos (PNDH) no que se refere às questões da educação em direitos humanos;

8) orientar políticas educacionais direcionadas para a constituição de uma cultura de direitos humanos;

18. Decreto $\mathrm{n}^{\mathrm{O}} 7.037$, de 21 de dezembro de 2009. 
9) estabelecer objetivos, diretrizes e linhas de ações para a elaboração de programas e projetos na área da educação em direitos humanos;

10) estimular a reflexão, o estudo e a pesquisa voltados para a educação em direitos humanos;

11) incentivar a criação e o fortalecimento de instituições e organizações nacionais, estaduais e municipais na perspectiva da educação em direitos humanos;

12) balizar a elaboração, implementação, monitoramento, avaliação e atualização dos Planos de Educação em Direitos Humanos dos estados e municípios;

13) incentivar formas de acesso às ações de educação em direitos humanos a pessoas com deficiência.

Por fim, em 30 de maio de 2012, foi publicada no Diário Oficial da União (DOU) a Resolução CNE/CP ${ }^{19} \mathrm{n}^{\mathrm{o}} 1$, que estabelece as Diretrizes Nacionais para a Educação em Direitos Humanos (DNEDH). Tal Resolução delibera uma série de normas pedagógicas a fim de consolidar a Educação em Direitos Humanos (EDH), as quais devem ser cumpridas pelos sistemas de ensino e suas instituições em todo país, da educação básica ao ensino superior. Destaco três artigos da referida Resolução ${ }^{20}$ :

Art. $3^{\circ}$ : A Educação em Direitos Humanos, com finalidade de promover a educação para a mudança e a transformação social, fundamenta-se nos seguintes princípios:

I- dignidade humana;

II- igualdade de direitos;

III- reconhecimento e valorização das diferenças e das diversidades;

IV-laicidade do Estado;

$\mathrm{V}$ - democracia na educação;

VI- transversalidade, vivência e globalidade; e

VII- sustentabilidade socioambiental.

Art. $5^{\circ}$ : A Educação em Direitos Humanos tem como objetivo central a formação para a vida e para a convivência, no exercício cotidiano dos Direitos Humanos como forma de vida e de organização social, política, econômica e cultural nos níveis regionais, nacionais e planetário.

Art. 9: A Educação em Direitos Humanos deverá estar presente na formação inicial e continuada de todos(as) os(as) profissionais das diferentes áreas do conhecimento.

19. Conselho Nacional de Educação/Conselho Pleno.

20. Disponível em: $\quad$ http://portal.mec.gov.br/index.php?option =com docman\&view $=$ download\&alias $=10889-$ rcp001-12\&category_slug $=$ maio $-2012-$ pdf\&Itemid $=30192$. Acesso em fev. 2018. 
Como se vê, são princípios que devem perpassar por toda a vida do cidadão brasileiro, seja na sua formação formal e não-formal, inicial e continuada. A entrada em vigor dessa Resolução foi um marco importante na inserção dos Direitos Humanos na educação nacional. De acordo com Ricardo Abreu (2015), na educação básica, a EDH se realiza por meio de suas várias modalidades e temas transversais, tais como: a educação de jovens e adultos (EJA), a educação especial, a educação quilombola, a educação indígena, a educação no campo, a educação ambiental e a educação das relações étnico-raciais. Na educação superior, houve a necessidade de se atualizar os planos de desenvolvimento institucionais (PDI) e os projetos políticos pedagógicos (PPP) dos cursos de graduação, sobretudo o dos cursos de formação inicial de professores de todas as áreas, incluindo ensino, pesquisa e extensão.

Segundo o autor, esses projetos inseriram os conhecimentos referentes à $\mathrm{EDH}$ em suas matrizes curriculares por três vias: $\mathrm{i}-$ ) a da transversalidade, com temas relacionados a direitos humanos trabalhados interdisciplinarmente; ii-) a da disciplinaridade, direitos humanos como um conteúdo específico de uma disciplina já existente no curso; iii-) a mista, combinando os formatos anteriores. Sempre respeitando as instâncias colegiadas de curso de cada instituição de ensino superior (IES). A ideia não é promover apenas um letramento em direitos bumanos, é preciso mais do que isso: o engajamento de todos da comunidade escolar, que todos os professores implementem os direitos humanos em suas matérias, que todos os sistemas de ensino e suas instituições, da escola à universidade, construam para si uma cultura de direitos bumanos, só assim consolidaremos uma EDH - conclui Abreu (2015).

Faz-se necessário explicar que quando tratamos de direitos humanos na educação estamos utilizando a concepção mais contemporânea do termo, aquela da Declaração Universal dos Direitos Humanos, de 1948, em comum acordo com a Organização das Nações Unidas (ONU) e com a Organização dos Estados Americanos (OEA). As DNEDH, em seu $\$ 1^{\circ}$ do art. $2^{\circ}$, estabelecem a diferença entre os conceitos de "educação em direitos humanos" e "direitos humanos". A primeira é conceituada, no documento, como um processo educacional constitutivo da cidadania, enquanto que os "direitos humanos" são um conjunto de direitos intrínsecos à condição humana, tendo como metaprincípios - termo de Abreu (2015) - a igualdade e a dignidade humana. Assim, a EDH transcende, metonimicamente, do ambiente escolar à sociedade; daí a feliz expressão de uma cultura em direitos bumanos, para além de um letramento em direitos bumanos. Até porque, como bem define o Comitê Nacional de Educação em Direitos Humanos (CNEDH), "a educação é tanto um 
direito humano em si mesmo, como um meio indispensável para realizar outros direitos". Defendo, portanto, que a Linguística Aplicada aponte e aposte nessa direção.

A entrada em vigor das novas Diretrizes para a EDH também refletiu diretamente, conforme o esperado, nas nossas avaliações oficiais, tanto da educação básica, como no Exame Nacional de Ensino Médio (ENEM), quanto da educação superior, como no Exame Nacional de Desempenho dos Estudantes (ENADE). No caso do ENEM, do qual tratarei mais adiante, um dos dispositivos de aferição da prova de redação do exame exige que os alunos elaborem, ao longo do seu texto dissertativo-argumentativo, uma proposta de intervenção para o problema abordado que respeite os direitos humanos, sob pena de tirarem zero em um dos critérios de correção (mais especificamente, na Competência V), caso descumpram esse comando da prova. Vale dizer que, até 2016, a nota zero nessa competência equivalia a ser eliminado do processo, pois o desrespeito aos direitos humanos era considerado uma falta grave. Em 2017, o Supremo Tribunal Federal (STF) mudou de ideia e interveio no exame, como contextualizarei na próxima seção.

\section{DIREITOS HUMANOS E ENEM: ENTRE AVANÇOS E RETROCESSOS}

O ENEM foi criado em 1998, portanto, completa vinte anos em 2018. A princípio, funcionou apenas como um instrumento de autoavaliação para os alunos concluintes do Ensino Médio. Era um exame facultativo e pago, por isso não conseguiu adesões em quantidades expressivas em suas primeiras realizações, contextualiza-nos Beth Marcuschi (2006). Em 2001, o MEC conseguiu praticamente impor o ENEM como uma alternativa parcial ou total à prova de ingresso no ensino superior, graças às políticas de convencimento junto às universidades e faculdades para que o exame nacional fosse gratuito para alunos oriundos de escolas públicas. Essa estratégia, reconhece Marcuschi (2006), deu maior visibilidade ao ENEM perante a sociedade, ao mesmo tempo em que os seus resultados passaram a funcionar não apenas como diagnósticos do ensino praticado no Ensino Médio no Brasil, como também o perfil dos estudantes dessa etapa de escolaridade passou a ser mensurado pelo exame, unificado nacionalmente.

A partir de 2009, sempre respeitando a autonomia das universidades, a utilização dos resultados do ENEM para o ingresso ao ensino superior passou a ocorrer como fase única de seleção (Sistema de Seleção Unificada - SISU) ou combinado com os processos seletivos próprios de cada Instituição de Ensino Superior (IES), que ainda opta por realizar o velho conhecido "vestibular" como 
prova de seleção. Atualmente, o ENEM é também utilizado para o acesso a programas oferecidos pelo Governo Federal, tais como o Programa Universidade para Todos (ProUni), o Fundo de Financiamento Estudantil (FIES) e o programa Ciência sem Fronteiras; esse último, até 2017, quando o programa fechou suas portas para estudantes da graduação.

É indiscutível a importância do ENEM como parte de uma política pública de avaliação da educação básica no Brasil e que tem o mérito de fazer convergir práticas educacionais em torno dos principais documentos norteadores da nossa educação, alinhando assim currículos e programas das escolas públicas e privadas do país. O exame merece comemorar seus vinte anos porque tem sobrevivido a duras críticas de uma torcida do contra: da mídia, que já o acusou de fraudes com a intenção de desestabilizá-lo; de algumas universidades públicas e privadas, que se incomodam com o sucesso do ENEM, uma vez que sempre lucraram com o comércio do vestibular; e recentemente, do próprio STF, que decidiu intervir no edital do exame e mudar as "regras do jogo" às vésperas da realização da sua prova de redação em 2017. Polêmicas lançadas são polêmicas discutidas.

No ENEM, o aluno deve escrever seu texto do tipo dissertativo-argumentativo para discorrer acerca de algum tema contemporâneo de importância nacional ou internacional, polêmico por excelência, e propor uma intervenção político-social que aponte para uma possível solução da questão abordada, desde que e sempre respeitando os direitos humanos, ou seja, requer que o aluno atue como cidadão. De acordo com Marcuschi (2006), esse é um exercício democrático no sentido em que estimula os jovens a transcenderem suas preocupações individuais e a se engajarem no mundo social e político que os cerca. Ao adotarem uma posição, um ponto de vista, uma atitude concreta em relação às questões do mundo contemporâneo, os jovens alunos estão desempenhando sua cidadania, fundamental no seu processo de formação. Não se trata de escrita retórica pura e simplesmente - acrescento - como se costuma fazer em textos desse tipo, no qual se prepara uma conclusão-síntese ao final para retomar estrategicamente os argumentos desenvolvidos na tessitura do texto. A produção textual do ENEM exige uma proposta de intervenção do aluno que ofereça uma solução para o problema colocado em questão - eis o diferencial do exame: uma conclusão-intervenção, o que permite que o aluno extrapole os argumentos já trabalhados ao longo do seu texto para elaborar algo novo, criativo, uma intervenção de engajamento social, que valorize a cidadania, a liberdade, a solidariedade e a diversidade cultural, ou seja, que respeite os direitos humanos. 
Além dessa preocupação fundamental com os direitos humanos, a Cartilha do Participante do ENEM, conhecida também como Manual de redação do ENEM ${ }^{21}$ sugere como seria o ideal dessa proposta na prova de redação:

A proposta de intervenção deve refletir os conhecimentos de mundo de quem a redige e, quando muito bem elaborada, deve conter não apenas a exposição da ação interventiva sugerida, mas também o ator social competente para executá-la, de acordo com o âmbito da ação escolhida: individual, familiar, comunitário, social, político, governamental e mundial. Além disso, a proposta de intervenção deve conter o meio de execução da ação e seu possível efeito, bem como o detalhamento da ação ou do meio para realizá-la. (BRASIL, 2017, p. 24)

Dito de outra forma, o exame requer que o aluno elabore uma proposta de intervenção detalhada, relacionando-a ao tema e articulada à discussão desenvolvida no texto. Não deve apenas expor a ação interventiva, deve também procurar responder às seguintes perguntas: $\mathrm{O}$ que (é possível fazer)? Quem (deve fazer, executar)? Como (se fazer, viabilizar)? Qual efeito (da proposta, suas consequências)? A proposta de intervenção é avaliada no critério de Competência $\mathrm{V}$ da grade de correção da prova de redação do ENEM, e pode valer de 0 a 200 pontos de acordo com os seis níveis de desempenho descritos para essa Competência.

As provas de redação do ENEM de 1998, 1999, 2000, 2002 e 2004 não exigiram dos alunos essa preocupação com os direitos humanos, porém, nas provas de 2001, 2003 e de 2005 a 2017, essa instrução tornou-se explícita na própria prova de redação. Os alunos deveriam atentar para os direitos humanos no ato de "selecionar, relacionar, organizar e interpretar fatos, opiniões e argumentos em defesa do seu ponto de vista", ou seja, para atender a Competência III i como também para atender a Competência V, descrita como "elaborar proposta de intervenção para o problema abordado, respeitando os direitos humanos". De 2009 (ano da PNDH-3) a 2012 (ano das DNEDH), a atenção aos direitos humanos foi se aperfeiçoando e alguns ajustes foram feitos no descritor da Competência $V$ até chegar ao que temos hoje. Em 2013, finalmente o edital do exame (INEP/ENEM n ${ }^{\circ} 1$, de 8 de maio de 2013) deu sua cartada final e determinou que o desrespeito aos direitos humanos levava a prova de redação como um todo à nota zero.

A partir de então, receberá nota zero a redação que desrespeitar, afrontar, agredir, ferir, explícita e deliberadamente, os direitos humanos, seja na proposta de intervenção, seja em qualquer outra parte do texto. Direitos Humanos tais como consagrados nos tratados internacionais e na Constituição da República Federativa do Brasil, entendidos como direitos fundamentais, valores, atos e comportamentos,

21.Disponível em: http://download.inep.gov.br/educacao_basica/enem/guia_participante/2017/manual_de redacao do enem_2017.pdf. Acesso em fev. 2018. 
nomeados e protegidos, que possibilitam a todos o direito a uma vida digna, à integridade, à liberdade, à intimidade.

E isso não é segredo para ninguém, sobretudo para os alunos que fazem o exame, pois a prova de redação do ENEM é transparente ao explicitar os critérios de anulação da redação nas próprias instruções da prova. É curioso observar como essas instruções foram alteradas ao longo dos últimos três anos do exame: de 2014 para 2015, a mudança foi sutil (de "insuficiente" para "texto insuficiente"); já na prova de 2017, a instrução ao aluno para não "desrespeitar os direitos bumanos" assumiu o primeiro posto dentre as demais instruções da prova, com se pode reparar em destaque itálico no quadro abaixo:

Quadro 2. Instruções para a redação da prova do ENEM (grifos nosso)

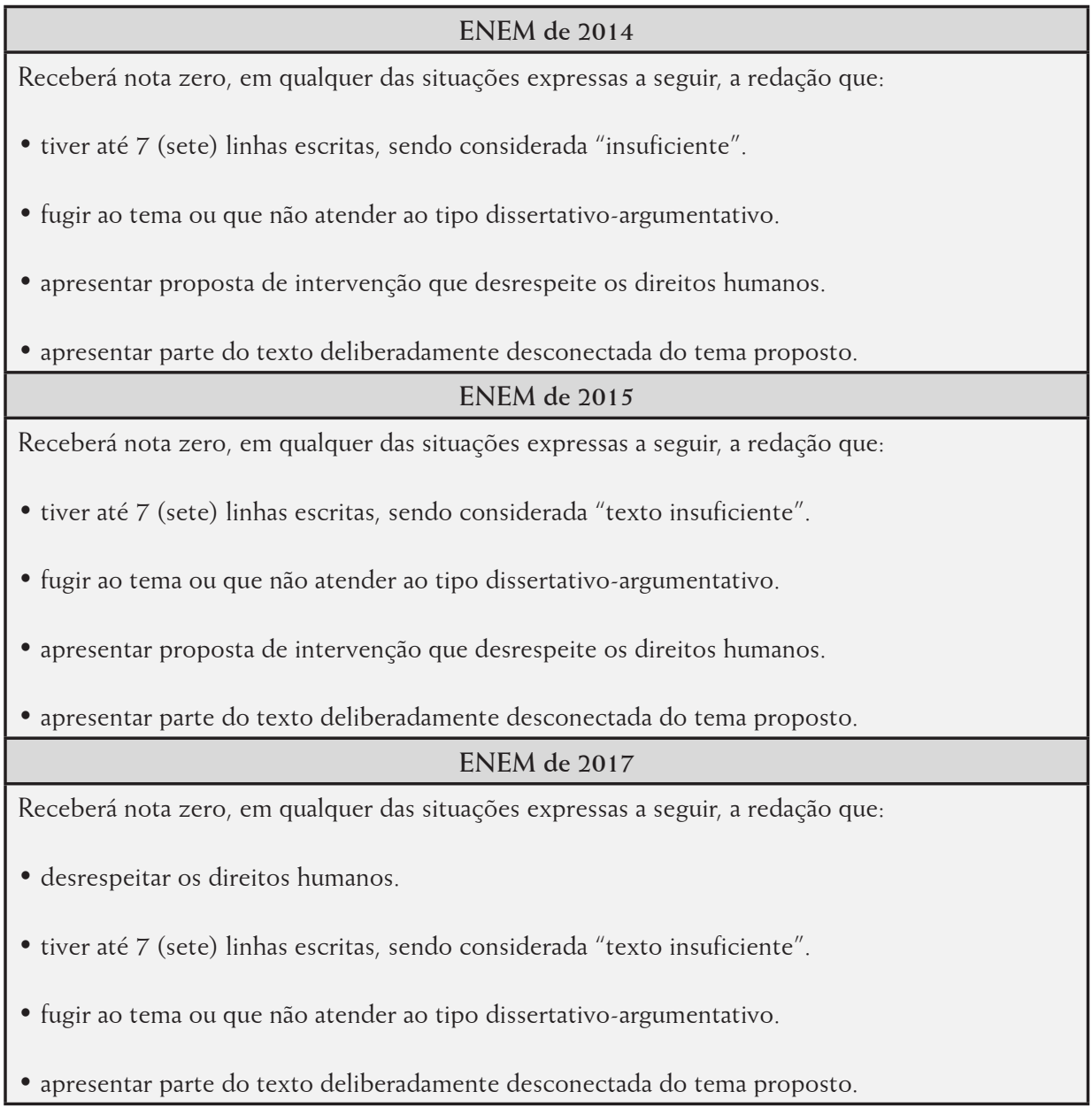


A supervalorização desse item não é gratuita. Ela responde diretamente aos documentos oficiais que regem as políticas públicas de Educação no Brasil, os quais foram apresentados anteriormente neste artigo, tais como: o Programa Nacional de Direitos Humanos (PNDH-3/2009), o Plano Nacional de Educação em Direitos Humanos (PNEDH/2006) e as Diretrizes Nacionais para a Educação em Direitos Humanos (DNEDH/2012), que por sua vez, baseiam-se na nossa Constituição Federal de 1988 e também em uma série de instrumentos internacionais de direitos humanos, como a própria Declaração das Nações Unidas sobre a Educação e Formação em Direitos Humanos (2011) e o Programa Mundial de Educação em Direitos Humanos (PMEDH 2005/2004).

Isso significa dizer que respeitar os direitos humanos não é simplesmente uma "invenção" da prova de redação do ENEM. Trata-se, antes de tudo, de um exercício de cidadania que, como já dito, não deve se restringir ao ambiente escolar (como um simples letramento em direitos bumanos), mas sim transcender a ele e abarcar o todo: a sociedade, o sertão, o mundo (uma cultura em direitos bumanos). Nesse sentido também, educar em direitos bumanos não é tarefa apenas dos professores de Linguagens para preparar alunos para fazer a prova de redação do ENEM, mas é um dever de todo e qualquer professor, não importa a área; é um dever de todo (bom) educador. Afinal, é objetivo da educação nacional e responsabilidade da escola,

a formação de um indivíduo capaz de se enxergar como parte de uma sociedade multicultural e multiétnica que tem como um dos seus princípios fundamentais a dignidade da pessoa humana e que objetiva promover o bem de todos, sem preconceitos de origem, raça, sexo, cor, idade e quaisquer outras formas de discriminação. (ABREU, 2015, p. 98)

\section{AS POLÊMICAS EM TORNO DAS PROVAS DE REDAÇÃO DO ENEM EM 2015 E EM 2017}

O que chama a atenção é que a instrução referente ao respeito aos direitos humanos assumiu o primeiro posto (cf. Quadro 2) justamente quando houve a interferência da Ministra Cármen Lúcia no edital do exame de 2017. Isso foi proposital ou não? Contextualizo. Em 25 de outubro do ano passado, o desembargador federal Carlos Moreira Alves, do Tribunal Regional Federal da $1^{\text {a }}$ Região (TRF-1), decidiu anular um trecho de um dos itens do edital do ENEM/2017, o qual determinava a nota zero para a redação que desrespeitasse os direitos humanos. As regras que definem as cinco competências exigidas na redação continuaram iguais, até mesmo a Competência $V$, já descrita acima, porém, a partir da nova decisão judicial, o 
desrespeito aos direitos humanos só poderá zerar a Competência V (o que significa menos 200 pontos na prova que vale mil) e não zero na redação como um todo. A assessoria de imprensa do TRF-1 justificou a suspensão desse item do edital por considerá-lo "uma ofensa à garantia constitucional de liberdade de expressão de pensamento e opinião", uma vez que a prova era anulada, sem a devida correção de seu conteúdo, "somente" por ser considerada desrespeitosa aos direitos humanos.

Ora, há um erro crasso de leitura da justiça nesse caso. Posso afirmar - não apenas com convicção, mas também com provas, afinal, fui corretora da prova de redação do ENEM por cinco anos - que nenbuma redação desse exame nacional é avaliada sem antes se fazer a devida leitura de seu conteńdo. O trabalho de correção consiste, antes de tudo, em ler todo o texto da redação, pois só assim, e somente assim, é possível detectar se há ou não algum desrespeito aos direitos humanos no texto do aluno. Portanto, não há nem nunca houve até então, uma "anulação automática" da redação, ou seja, zerála sem ao menos lê-la para saber se ela viola ou não os direitos humanos, como foi argumentado por aqueles que se colocaram a favor da decisão judicial.

A Advocacia Geral da União (AGU) e a Procuradoria Geral da República (PGR) recorreram para tentar suspender a decisão liminar do TRF-1, o que foi em vão. A Ministra Cármen Lúcia, atual presidente do STF, rejeitou os pedidos apresentados e acatou a decisão do TRF-1. Nas palavras da Exma ${ }^{a}$, em entrevista ao G1, portal de notícias da Globo: "Não se desrespeitam direitos humanos pela decisão que permite ao examinador a correção das provas e a objetivação dos critérios para qualquer nota conferida à prova. $\mathrm{O}$ que os desrespeitaria seria a mordaça prévia do opinar e do expressar do estudante candidato"22. O MEC e o Instituto Anísio Teixeira (INEP), responsáveis pela aplicação do exame, decidiram acatar a decisão do Supremo e não recorrer, até porque isso ocorreu dia 04 de novembro, literalmente às vésperas do ENEM/2017. O mais grave ainda, é que a decisão do TRF-1 foi tomada em caráter de urgência a pedido da Associação do Escola Sem Partido, tendo em vista, justamente, a proximidade do exame.

Não é possível compreender a que "mordaça prévia do opinar e do expressar do estudante" a Ministra se refere, pois como já explicado anteriormente, o aluno não é proibido de opinar nem de se expressar, desde que não desrespeite os direitos humanos; além do que, a avaliação não é prévia, dá-se pós-leitura do texto do aluno. O argumento de Cármen Lúcia, de certa forma, corrobora a alegação do Escola Sem Partido, que defende que "ninguém é obrigado a dizer o que não pensa para poder ter acesso às universidades". E dizer o que desrespeita os direitos humanos,

22.Disponível em: https://g1.globo.com/educacao/noticia/enem-mec-diz-que-acata-decisao-do-supremo-e-que-nao-vai-anular-redacao-contraria-aos-direitos-humanos.ghtml. Acesso em nov. 2017. 
pode? Claro que não. A associação alega, dentre muitos outros absurdos, que falta ao INEP e aos corretores um referencial objetivo do que se entende por direitos humanos $^{23}$. Os simpatizantes do movimento deveriam então, tomar conhecimento não só da Constituição, mas de outros documentos nacionais, organizações e comitês internacionais, que explicam, sustentam e defendem os direitos humanos. A decisão do Supremo foi comemorada, com ironia, pela organização do Escola Sem Partido em sua página do facebook.

Contudo, essa não foi a primeira vez que a prova de redação do ENEM se tornou alvo da mídia. Em 2015, quando o tema da prova de redação foi A persistência da violência contra a mulher na sociedade brasileira, chamou a atenção o número de textos que tiravam nota zero na Competência $\mathrm{V}$ e, por conseguinte, na redação inteira. $\mathrm{O}$ motivo era porque os alunos apontavam como proposta de intervenção para o tema discutido atos que desrespeitavam os direitos humanos, tais como ações que incitavam igualmente a violência e obedeciam à lógica do "olho por olho, dente por dente". Exemplos do tipo ${ }^{24}$ : "o estuprador da mulher deve ser também estuprado"; "o agressor deve ser massacrado na cadeia", "ir para a prisão não é o bastante: o homem que violentasse uma mulher deveria ser linchado em praça pública", "todos os estupradores devem ser castrados", etc. Enfim, não faltavam sugestões com requintes de crueldade para solucionar o problema da violência contra a mulher no Brasil.

A organização responsável pela realização do ENEM em 2015, pressionada pela mídia (ou pelo Escola Sem Partido?), que procura sempre tornar o exame um vexame nacional, solicitou à Secretaria de Direitos Humanos acompanhamento especial ao processo de correção. Desse modo, toda e qualquer redação que tirasse nota zero por ferir os direitos humanos era devidamente encaminhada a uma equipe de advogados da SDH para o parecer final. As redações que propusessem "apenas" pena de morte ${ }^{25}$ ou prisão perpétua, sem contudo ferir a integridade física do ser humano, não se caracterizavam como um desrespeito aos direitos humanos e, portanto, não zeravam. Já as redações que apelassem para intervenções violentas, tais como as exemplificadas acima, essas sim, configuravam desrespeito aos direitos

23. A petição inicial do Escola Sem Partido encontra-se disponível em:

http://www.escolasempartido.org/images/ENEM.pdf. Acesso em nov. 2017.

24. Os exemplos aqui apontados são fictícios, baseados na memória que guardo daqueles textos que corrigi na ocasião.

25.A SDH nos esclareceu que a "pena de morte" não caracteriza desrespeito aos direitos humanos desde que sentenciada pelo Estado. Só podem ser consideradas desrespeito aos direitos humanos as propostas de intervenção que firam a integridade física do ser humano, que o levem a um justiçamento, por exemplo. 
humanos. Todas as anulações foram revistas pelos corretores e em seguida passaram pelo crivo da SDH. Modalização ou censura? Cuidado.

O tema da prova de redação do ENEM/2015 foi um marco justamente por tratar de questões caras aos direitos humanos: violência contra a mulher, feminicídio, Lei Maria da Penha. Tudo o que não valeu de nada para a mídia que, mais uma vez, colocou em xeque a qualidade da correção e dos corretores; e para o Escola Sem Partido, que considerou uma afronta o nosso exame nacional tratar de gênero em sua prova de redação e trazer uma citação de Simone de Beauvoir ${ }^{26}$ em uma questão da prova de Ciências Humanas. Se de um lado os assuntos tratados nas provas e a parceria com a SDH representam avanços; de outro lado, a interferência midiática e os ecos do Escola Sem Partido conotam retrocessos que facilmente ganham credibilidade no meio social.

É comum, por exemplo, jornais e revistas estamparem notícias referindo-se aos desvios à norma culta padrão nas redações do ENEM. Muitos leitores ficam indignados com a nota mil atribuída a um texto em que "paralisação" está escrita com " $z$ " e não com " $s$ ". Entretanto, não ficam igualmente indignados quando redações de alunos defendem a castração de todos os estupradores (na prova de 2015), ou o linchamento daqueles que frequentam terreiros de candomblé (na prova de 2016), ou ainda, que surdo não deveria ter o direito de ir à escola (na prova de 2017) ${ }^{27}$. Propostas de intervenção desse tipo é que deveriam provocar polêmicas na mídia e chocar o público leitor, não a falta de uma crase ou de uma vírgula.

\section{CONSIDERAÇÕES FINAIS}

Ainda no que se refere ao desrespeito aos direitos humanos na prova de redação do ENEM/2015, Marcelo Soares (2017) ${ }^{28}$, jornalista, fez uma pesquisa bastante interessante com os microdados da prova, tornados públicos pelo INEP, e traçou o perfil dos participantes que zeraram por esse motivo. Dos 9. 935 que desrespeitaram os direitos humanos e tiveram suas redações anuladas, $60,1 \%$ eram meninas e 39,9\% eram meninos. Provavelmente porque são alunas que propuseram retaliações, as quais não constam no nosso Código Penal, aos homens violentos.

26.A célebre frase de Simone de Beauvoir : "Não se nasce mulher, torna-se mulher" foi citada em uma questão da prova de Ciências Humanas que tratava das lutas feministas da metade do século XX.

27. Eis os temas da prova de redação do ENEM nos últimos três anos: A persistência da violência contra a mulher na sociedade brasileira (2015), Caminhos para combater a intolerância religiosa no Brasil (2016) e Desafios para a formação educacional de surdos no Brasil (2017).

28.Disponível em: https://medium.com/numeralha/os-eliminados-na-reda\%C3\%A7\%C3\%A3o-doenem-n\%C3\%A3o-s\%C3\%A3o-quem-voc\%C3\%AA-imagina-47bc2acaa9e. Acesso em nov. 2017. 
Outros dados interessantes sobre os participantes que tiraram nota zero na redação por ferir os direitos humanos foram levantados pelo jornalista, tais como: o tipo de escola onde cursaram o fundamental; quantos desses trabalham ou já trabalharam ou não trabalham; se sim, por quantas horas semanais; qual a profissão de seus pais; qual escolaridade do pai; qual a escolaridade da mãe; e por fim, qual a renda familiar dos eliminados na prova e dos não eliminados.

Desses microdados, dois particularmente interessam aqui: os que dizem respeito à escolaridade dos alunos que fizeram a prova do ENEM em 2015 e à renda familiar de suas famílias, o que diz muito sobre a condição social em que vivem:

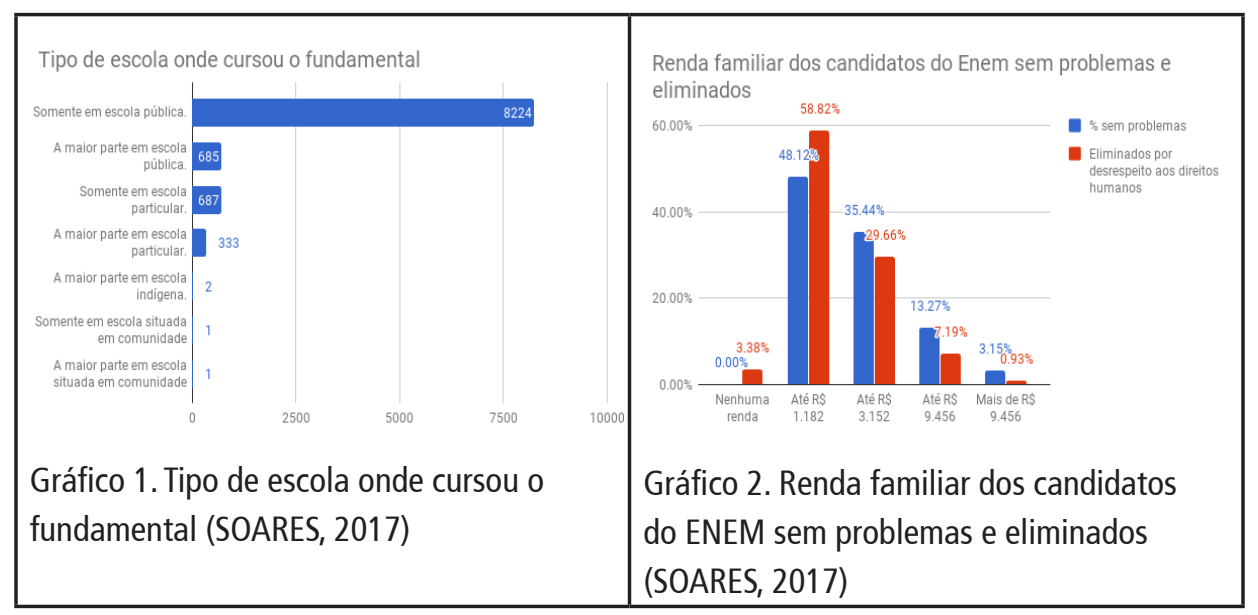

No primeiro gráfico, temos que, desses eliminados, 8.224 só estudaram em escolas públicas; 685 estudaram a maior parte em escolas públicas; 687 somente em escolas particulares e 333 estudaram a maior parte em escolas particulares. No segundo gráfico, o que a legenda chama de "\% sem problemas" são os participantes que não zeraram por desrespeitar os direitos humanos. Nota-se que $58,82 \%$, ou seja, mais da metade dos alunos com baixa renda familiar (próxima a um salário mínimo: de até $\mathrm{R} \$ 1.182,00)$ foram eliminados por ferir os direitos humanos. Dados que podem nos levar a uma interpretação simplista e até mesmo preconceituosa: a de que são os pobres, logo, estudantes de escolas públicas, quem mais desrespeita os direitos humanos no Brasil.

Não é verdade. O que não consta nos gráficos, mas nós, docentes, sabemos por experiência em campo, é que os alunos com melhor renda familiar (das classes A e B), portanto aqueles que estudam em escolas particulares, são "treinados" pelos seus professores de ensino médio e cursinho a não cometerem "esse deslize" na prova, sobretudo na elaboração da proposta de intervenção. São alunos que têm 
aulas especiais de redação para o ENEM, têm seus textos corrigidos segundo a grade oficial do exame, e quando deixam escapar em suas redações argumentos fascistas, são imediatamente "corrigidos" e instruídos pelos seus professores-corretores a não escreverem nada parecido na situação real do exame. Já os alunos pertencentes a famílias de baixa renda (das classes C, D e E), portanto aqueles que estudam em escolas públicas, esses, na grande maioria, nem sequer têm aulas de redação em suas escolas; nunca ouviram falar em grade de correção do ENEM; não foram instruídos tampouco treinados pelos seus professores para não desrespeitarem os direitos humanos em seus textos. São vítimas da violência, talvez por isso a tratem com certa naturalidade, o que, por vezes, reflete em suas redações.

Soube, igualmente por experiência em campo, e por meio de professores da rede privada de ensino, que seus alunos festejaram, juntamente com a mídia e com o Escola Sem Partido, quando o STF decidiu alterar o edital do ENEM/2017 e não mais anular as redações que desrespeitassem os direitos humanos, pois antes, eles, alunos, se sentiam lesados em não poderem expressar seus desejos fascistas em suas produções textuais. Seria essa a mordaça à qual a Ministra Cármen Lúcia se referia? Escola Sem Partido e mídia aplaudiram a intervenção da Exmª e e os alunos se sentiram premiados com uma suposta liberdade de expressão que não disfarça discurso de ódio nem respeita direitos humanos. Digo e redigo: retrocesso!

Por isso, mais uma vez insisto, ampliando a ideia de Abreu (2015) e ancorada em Street (2014), que não basta investir em um letramento autônomo em direitos bumanos, o qual privilegia, sobretudo, alunos de escolas particulares; é preciso apostar em uma cultura em direitos bumanos, ou melhor, em um letramento ideológico em direitos bumanos, por meio do qual se comungue educação e direitos humanos, que envolva tanto alunos de escolas de ensino público quanto privado, o sertão e o mundo.

Por fim, tomo emprestada a epígrafe de João Guimarães Rosa no início deste artigo para confessar que: o que conto aqui é apenas o resumo, pois no estado atual do viver, não sei se o dia é para esperança ou para a desconsolação.

\section{REFERÊNCIAS}

ABREU, R. N. (2015). Exercício da cidadania e direitos humanos: as funções da competência V na redação do ENEM. In. SILVA, L. R. da; FREITAS, R. M. K. (Org.). Linguagem, interação e sociedade: diálogos sobre o ENEM. João Pessoa: Editora do CCTA. pp. 97 108.

BRASIL. Constituição da República Federativa do Brasil: texto constitucional promulgado em 5 de outubro de 1988. Brasília: Senado Federal, coordenação de Edições Técnicas, 
2016. 496 p. Disponível em: https://www2.senado.leg.br/bdsf/bitstream/handle/ id/518231/CF88_Livro_EC91_2016.pdf. Acesso fev. 2018.

BRASIL. Lei de Diretrizes e Bases da Educação Nacional. Lei No 9.394 de 20 de dezembro de 1996. Disponível em: http://portal.mec.gov.br/seesp/arquivos/pdf/lei9394_ldbn1.pdf. Acesso fev. 2018.

BRASIL. Programa Nacional de Direitos Humanos (PNDH-3) / Secretaria Especial dos Direitos Humanos da Presidência da República. Versão digital e atual. Brasília: SEDH/PR, 2010, 308p. Disponível em: http://www.sdh.gov.br/assuntos/direito-para-todos/ programas/pdfs/programa-nacional-de-direitos-humanos-pndh-3. Acesso fev. 2018.

BRASIL. Plano Nacional de Educação em Direitos Humanos (PNEDH) / Comitê Nacional de Educação em Direitos Humanos. Brasília: Secretaria Especial dos Direitos Humanos, Ministério daEducação, Ministério daJustiça, UNESCO, 2007.76 p. Disponível em: http://portal. mec.gov.br/index.php? option $=$ com_docman\&view $=$ download\&alias $=2191$ - planonacional-pdf\&category_slug $=$ dezembro-2009-pdf\&Itemid $=30192$. Acesso em fev. 2018.

BRASIL. Educação em Direitos Humanos: Diretrizes Nacionais (DNEDH). Brasília: Coordenação Geral de Educação em SDH/PR, Direitos Humanos, Secretaria Nacional de Promoção e Defesa dos Direitos Humanos, 2013. 76p. Disponível em: http:// www.sdh.gov.br/assuntos/conferenciasdh/12a-conferencia-nacional-de-direitoshumanos/educacao-em-direitos-humanos/caderno-de-educacao-em-direitoshumanos-diretrizes-nacionais. Acesso em fev. 2018.

BRASIL. Redação do Enem 2017: Cartilha do participante. Instituto Nacional de Estudos e Pesquisas Educacionais Anísio Teixeira (INEP). Rev. Externa: Fundação para o Vestibular da Universidade Estadual Paulista Júlio de Mesquita Filho - Fundação Vunesp. Brasília, 2017. Disponível em: http://download.inep.gov.br/educacao_ basica/enem/guia_participante/2017/manual_de_redacao_do_enem_2017.pdf. Acesso em fev. 2018.

CANDIDO, A. (1995) O direito à literatura. In: Vários escritos. $3^{\mathrm{a}}$ ed. rev. e ampl. São Paulo: Duas Cidades, pp. 171-193.

LAPA, F. (2018) O advocacy na ONU sobre a educação em direitos humanos no Brasil. In: Cadernos da Defensoria Pública do Estado de São Paulo, v. 3, n. 8, pp. 86-91. 
LEÃO, I. V.; BARWINSKI, S. L. L. B. (2018). Direitos humanos e igualdade de gênero no Brasil: tensões no direito à educação na ONU e OEA. In: Cadernos da Defensoria Pública do Estado de São Paulo, v. 3, n. 8, pp. 56-70.

MARCUSCHI, B. (2006) O que dizem o SAEB e o ENEM sobre o currículo de língua portuguesa para o ensino médio. In: BUNZEN, C.; MENDONÇA, M. (Orgs.) Português no ensino médio e formação de professor. São Paulo: Parábola Editorial, pp. 57-82.

NEVES, C. A. de B. (2014). A literatura no ensino médio: os gêneros poéticos em travessia no Brasil e na França. Tese de Doutorado em Linguística Aplicada. Instituto de Estudos da Linguagem, Unicamp, Campinas.

PRATA, A. R. S.; SOUZA, P. S. M. de. (2018). Apesar de Você, Amanhã há De SER outro dia: análise das consequênCias da efetivaÇão de programas como "Escola Sem PARTIDO". In: Cadernos da Defensoria Pública do Estado de São Paulo, v. 3, n. 8, pp. 77-85.

PINTO, R. (2012) Museus e diversidades sexual: reflexões sobre mostra LGBT e queer. Revista de Arqueologia Pública, v. 5, n. 1, pp. 44-55.

ROSA, J. G. (1967). Grande sertão: veredas. Rio de Janeiro: Livraria José Olympio.

SOARES, M. Os eliminados na redação do Enem não são quem você imagina. In: O homem que conversa com os dados. Disponível em: https://medium.com/numeralha/oseliminados-na-reda\%C3\%A7\%C3\%A3o-do-enem-n\%C3\%A3o-s\%C3\%A3o-quemvoc\%C3\%AA-imagina-47bc2acaa9e. Acesso em nov. 2017.

STREET, B. (2014). Letramentos sociais: abordagens críticas do letramento no desenvolvimento, na etnografia e na educação. Trad. Marcos Bagno. São Paulo: Parábola.

Mais links consultados:

https://www.defensoria.sp.def.br/cadernos_defensoria/volume8.aspx. Acesso em fev. 2018.

http://www.deolhonosplanos.org.br/projetos-lei-escola-sem-partido/. Acesso em fev. 2018.

http://escolasempartido.org/flagrando-o-doutrinador. Acesso em fev. 2018.

http://escolasempartido.org/planeje-sua-denuncia. Acesso em fev. 2018.

http://www.escolasempartido.org/artigos-top/552-modelo-de-notificacao-extrajudicialarma-das-familias-contra-a-doutrinacao-nas-escolas. Acesso em fev. 2018. 
http://escolasempartido.org/deveres-do-professor. Acesso em fev. 2018.

http://pne.mec.gov.br/images/pdf/pne_conhecendo_20_metas.pdf. Acesso em fev. 2018.

secadi@mec.gov.br. Acesso em fev. 2018.

http://educacaointegral.org.br/reportagens/projeto-de-lei-preve-prisao-de-docente-quefalar-sobre-ideologia-de-genero/. Acesso em maio 2016.

https://iddh.org.br/instituto/. Acesso em fev. 2018.

http://www.sdh.gov.br/assuntos/direito-para-todos/programas/pdfs/programa-nacional-dedireitos-humanos-pndh-3. Acesso em fev. 2018.

http://portal.mec.gov.br/index.php?option $=$ com_docman\&view $=$ download\&alias $=2191$ plano-nacional-pdf\&category_slug $=$ dezembro-2009-pdf\&Itemid=30192. Acesso em fev. 2018.

http://www.sdh.gov.br/assuntos/conferenciasdh/12a-conferencia-nacional-de-direitoshumanos/educacao-em-direitos-humanos/caderno-de-educacao-em-direitos-humanosdiretrizes-nacionais. Acesso em fev. 2018.

http://portal.mec.gov.br/index.php?option $=$ com docman\&view $=$ download\&alias $=10889-\mathrm{rcp} 001-12 \&$ category slug $=$ maio $-2012-$ pdf\&Itemid=30192. Acesso em fev. 2018.

https://g1.globo.com/educacao/noticia/enem-mec-diz-que-acata-decisao-do-supremo-eque-nao-vai-anular-redacao-contraria-aos-direitos-humanos.ghtml. Acesso em nov. 2017.

http://www.escolasempartido.org/images/ENEM.pdf. Acesso em nov. 2017.

Recebido: 21/04/2018

Aceito: $12 / 07 / 2018$ 